\title{
An Estimation of Technical Efficiency of Tea Smallholdings in Ratnapura District of Sri Lanka
}

\author{
Sandunika Jayakody, Sajitha Dishanka \\ Department of Business Economics, University of Colombo, Sri Lanka \\ sandunikahansani1991@gmail.com, sajitha@dbe.cmb.ac.lk
}

\begin{abstract}
While accepting the fact that the tea smallholdings sector of Sri Lanka immensely contribute to the annual tea output of the economy, the sector still faces various deficiencies due to problems pertaining to input related issues. Measuring the level of efficiency and identifying the factors which are attributed to inefficiency are in utmost importance in introducing remedies for that. A cross sectional survey was conducted on a sample of tea smallholders in Ratnapura district where highest contribution to the total tea production of the country is made. In this study, the Cobb-Douglas Stochastic production frontier model was used by incorporating the technical inefficiency effect model to estimate the level of technical efficiency in tea smallholdings sector. The study revealed that average technical efficiency of tea smallholdings sector in the study area was 87.36 percent that keeps a margin of 12.64 percent for further improvements through better use of available resources and technology. The results of the Cobb-Douglas model revealed that the estimated coefficients of land, labor and fertilizer are positively and significantly affect the green leaves production of the sector. The findings of the inefficiency model disclosed that age, farming experience, level of education, occupation, age of tea plants, farming group membership and credit access have significant negative impact on technical inefficiency.
\end{abstract}

Keywords: Ratnapura district, Sri Lanka, Stochastic Frontier Approach, Tea smallholdings, Technical efficiency.

\section{Introduction}

Tea is one of the most prominent plantation crops in Sri Lankan agricultural sector, contributing heavily to the development of Sri Lankan economy through generating foreign exchange and creating employment opportunities. Sri Lanka is well-known for its high quality black tea and is one of the largest tea producers and exporters in the world. At present, Sri Lanka has become fourth largest tea producer and third largest tea exporter in the world. It accounts for approximately 2 percent of the gross domestic product (GDP) and, generating annually US\$1,325 million foreign exchange to the economy (Central Bank, 2013). Currently, tea sector provides direct and indirect employment to more than one million people in the country. As a result, it has become the main income source of large number of estates and rural farmers in Sri Lanka. The total tea lands in the country recorded as 204,024 hectares, of which smallholdings sector holds 59 percent and 41 percent by the plantation sector (Ministry of Plantation Industries, 2013). Currently, tea smallholdings sector takes a larger portion of the whole tea industry as it contributes 71.4 percent to the total made tea production of the country (TSHDA, 2012). Tea cultivation is scattered in many parts of the low-country, mid-country and up-country wet zones in Sri Lanka. Among these wet zones, low-country is the largest tea cultivating region with a contribution of 61 percent to the total tea production of the country (Ministry of Plantation Industries, 2013). It accounts for 89,176 hectares of cultivated tea lands in Ratnapura, Galle, Matara, Kegalle and Kalutara districts in Sri Lanka.

There are 314,021 tea smallholders scattered in low-country who grow tea in their small blocks of land. They contribute 82 percent to the total smallholders' tea production of the country (TSHDA, 2012). In low-country, the largest smallholders' tea cultivating region is Ratnapura district and it takes a larger portion of the country's total smallholders' tea production. Tea industry has expanded their production by increasing the performance of the tea smallholdings sector during the last two decades. As a result of that Sri Lankan total tea production predominantly depends on the production possibility of tea smallholdings sector, especially in low-country. Although, tea smallholdings sector performs better than the tea plantation sector, this sector has been fronting several problems which are both technical and behavioral. Some of these are low productivity, increasing cost of production, falling export prices, irrational use of fertilizers, ineffective tea varieties used in cultivation and unexpected adverse climatic changes (TSHDA, 2012). These factors have kept Sri Lanka at a relatively lower level of tea production when compared with the other leading tea producing countries such as China, India and Kenya. Thus, it is primarily required either changing existing technology or increasing the quantity of inputs that uses for the green leaves production in order to increase the production capacity of the 
tea smallholdings sector. Although these two options are viable in increasing the green leaves production, it requires a considerable cost or investment as well.

Most of smallholders are with less capacity to expand their existing production volume as they are lacking financial capabilities. Therefore, it is difficult to incur a higher cost for changing technology and applying more inputs in the short-run. The term technical efficiency is identified as maximization of the output from a given level of inputs with the given technology. Farmers' ability to increase existing level of output from a given set of inputs can be identified by measuring the technical efficiency of tea smallholdings sector. If farmers are maintaining very low level of technical efficiency, apparently it stresses that they can further increase their output from existing inputs by reducing inefficiencies of their production. Eventually, this would probably be significant as it positively affects the economic efficiency as well through cost minimization. Therefore, this study intends to estimate the technical efficiency and identify the determinants of technical efficiency of tea smallholders in low-country wet zone in Sri Lanka. Moreover, the paper is concluded with vital resolutions to improve the technical efficiency of tea smallholdings sector of Sri Lanka, which would probably give insights to the tea plantation sector as well, which at present undergoes the identical problem of optimizing its resources.

Research Problem: As a rapidly growing sub sector in Sri Lankan agricultural economy, tea smallholdings sector needs to attend in maximizing efficiency in utilization of its existing resources in order to get the maximum possible green leaves production. More precisely, the farmers who engaged in this sector need to be technically efficient. Although this sector performs comparatively well, evidence witness that it operates below the potential level due to the inefficiency component in their production process. A study on the estimation of technical efficiency in mid-country tea smallholdings sector (Basnayaka \& Gunaratne, 2002) has found that the average technical efficiency level is 63.1 percent suggesting smallholders in mid-country have larger possibility to increase their output through improvements in technical efficiency. Low-country tea smallholdings sector is the largest contributor which greatly drives to achieve the major target of Sri Lankan tea industry of being the world's largest made tea producing country.

Hence, it is unarguably important to explore, if tea smallholders in low-country is also in this aforementioned inefficiency dilemma in utilizing their existing resources. Therefore, this study addresses whether tea smallholders in Ratnapura district in low-country are potentially capable of improving their green leaves production without incurring any additional input cost. In the light of this exploration, it will probably be an opportunity for them to improve the level of efficiency by conquering inefficiencies. Thus, this study researched low-country smallholdings sector to estimate their technical efficiency level to identify their ability to obtain maximum green leaves production from a given set of inputs and available technology. Therefore, the outcomes of this study would probably provide insights to tea smallholders in maximizing their output by optimizing their existing resources. Further, these study outcomes would provide implications to responsible authorities of the tea industry in directing the tea smallholders in improving the efficiency.

\section{Literature Review}

The Concept and Measurement of Technical Efficiency: Technical efficiency is an important element of productive efficiency and it is derived from the production function (Førsund, Lovell, \& Schmidt, 1980). Thus, technical efficiency can be conceptualized as the maximum achievable level of output for a given level of inputs, given the current level of alternative technologies available (Ellis, 1993). The production frontier was developed to measure productive efficiency and it defines the limit to a range of possible observed production levels which identifies the extent to which the firm lies below or above the frontier (Farrell, 1957). The concept of efficiency is linked with this frontier model and subsequently applied by many researchers in their work related to productive efficiency [ (Afriat, 1972), (Aigner, Lovell, \& Schmidt, 1977), (Førsund, Lovell, \& Schmidt, 1980), (Kumbhakar \& Lovell, 2004)].

The two major approaches to measure the technical efficiency are parametric frontier approach and nonparametric frontier approach. Non-parametric frontier approach neither imposes the functional form on the production frontiers nor makes assumptions about the error term. It assumes all the deviations from the 
frontier occur as a result of the inefficiency of the firm. The parametric approach which is known as 'Stochastic frontier approach' imposes a functional form on the production frontier. The frequently adopted functional forms are the Cobb-Douglas production function and trans-log production function. The stochastic frontier approach assumes that deviations from the frontier occur due to random effects (reflecting measurement errors and statistical noise) and also due to firm specific inefficiency [ (Battese, 1992), (Coelli, Rao, \& Battese, 1998)].

The parametric frontier approach adopts econometrics method to estimate parameters of both stochastic frontier production function and inefficiency effect model. The major advantage of stochastic frontier approach is that, it includes stochastic random noises in addition to the inefficiency effect, which are uncontrollable. The main disadvantage of this approach is that it executes explicit constraint on functional forms and distributional assumption for one-sided error term (Battese \& Coelli, 1995). The literature further suggests two methodological approaches to analyze the sources of technical efficiency which is based on stochastic production function. The first approach is called the "two stage estimation procedure" in which, the stochastic production function is estimated first and then efficiency scores are derived. In the second stage, the derived efficiency scores are regressed based on explanatory variables by using Tobit regression or ordinary least square method. The second approach is known as "one stage simultaneous estimation approach" (Battese \& Coelli, 1995). According to this approach, the inefficiency effects are generally explained as an explicit function of a vector of farm specific variables or characteristics. Thus, the parameters of the frontier production function are concurrently estimated with those of an inefficiency model, in which the technical inefficiency effect is specified as a function of other variables or characteristics (Chirwa, 2007).

Determinants of Technical Efficiency in Agriculture: Although literature on technical efficiency is in abundance, research studies on technical efficiency in tea smallholdings sector are relatively scarce even in the global context. Most agriculture related technical efficiency estimation studies have used similar type of variables for their studies. This approach has been criticized on the ground that the firm's knowledge of its level of technical inefficiency has an impact on its inputs choices and thus inefficiency can be dependent on the explanatory variables. The variables such as farmer's age, education level of the farmer, access to extension, access to credit, agro-ecological zones, farmer's family size, land holding size, number of plots owned, gender, tenancy, market access, farmer's access to fertilizer, agrochemicals, improved seeds, membership of farmers' associations were reported by many studies where a positive effect on technical efficiency could be identified [ (Amos, 2007), (Ahmad, Chaudhry, \& Iqbal, 2002), (Kibaara, 2005), (Basnayaka \& Gunaratne, 2002)]. According to the results of a similar study where stochastic frontier model was applied, inefficiency model has shown that age of farmer, education, occupation, type of crop (VP or seedling) and type of clone have significant effect on efficiency (Basnayaka \& Gunaratne, 2002).

It further has shown that coefficient of education, age of farmer, occupation and type of crop are positively correlated and type of clone is negatively correlated with technical efficiency. Approximately, similar results were identified in a study on sugarcane production in Tanzania in which variables such as age, education and experience have positive relationship with technical efficiency (Msuya \& Ashimogo, 2006). A study on tea farmers in Northern Mountainous region in Vietnam has also used Cobb- Douglas stochastic frontier production function to estimate the tea yield and production efficiency of tea farmers in the study area (Hong \& Yabe, 2015). The researchers have found the mean technical efficiency level of tea farmers in the study area was 89.6 percent and further explained that the farmers have ability to increase their average output by 10.4 percent by using given level of inputs and technology. In contrast, a study on agricultural extension and technical efficiency of tea production in Northeastern Vietnam explained that tea production in this region suffered a strong inefficiency because its average technical efficiency was recorded very low value of 32 percent (Nguyen-Van \& To-The, 2016). There are 97,984 smallholdings scattered in 17 divisional secretariats (DS) and 482 Grama Niladhari (Village Officer) divisions in Ratnapura district (TSHDA, 2012).

Although they had used the trans-log production function to estimate the technical efficiency, the results of the study evidenced that Cobb-Douglas production function would have been more appropriate. Another study which has used stochastic production function to predict the technical inefficiency effect of paddy farmers has estimated the Cobb-Douglas production function for total value of output as a function of land, labor, bullocks and cost including fertilizer, manure, pesticides, machinery, etc (Battese \& Coelli, 1995). The 
results have suggested that the estimated coefficients of the land and labor were highly significant despite the fact that the cost of other inputs showed relatively small but significant values. The results of the inefficiency model revealed that, educated and older farmers are more technically efficient than less educated and young farmers. Therefore, human capital variables such as farmers' age and years of education affect farmers' capability to utilize inputs in a cost-minimizing way (Wadud, 2003). Thus, the cost of inefficiency can be reduced by providing more education, extension services for expansion and propagation of modern techniques of production and provision of credit to rural sector (Parikh, Ali, \& Shah, 1995).

\section{Research Methods}

The study was conducted in Ratnapura district which belongs to the Sabaragamuwa province in low-country wet zone in Sri Lanka. It is the largest smallholders' tea cultivating region in low-country with a total extent of smallholder tea lands of 30,441 hectares (TSHDA, 2012). Kuruwita and Pelmadulla divisional secretariats were selected for the sampling frame on the ground of being the largest green leaves producing areas in Ratnapura district. There are approximately 10,500 tea smallholders engaged in tea cultivation in both the divisions (TSHDA, 2012). Besides, these areas are well-known for favorable soil and weather conditions for growing tea. The sample size was determined based on $7 \%$ margin of error. Accordingly the sample size was determined as follows. The sample size (n) is calculated according to the formula:

$\mathrm{n}=[\mathrm{z} 2 * \mathrm{p} *(1-\mathrm{p}) / \mathrm{e} 2] /[1+(\mathrm{z} 2 * \mathrm{p} *(1-\mathrm{p}) /(\mathrm{e} 2 * \mathrm{~N}))]$

Where: $\mathrm{z}=1.96$ for a confidence level $(\alpha)$ of $95 \%, \mathrm{p}=$ proportion, $\mathrm{N}=$ population size, $\mathrm{e}=$ margin of error. $\mathrm{z}=1.96, \mathrm{p}=0.5, \mathrm{~N}=10500, \mathrm{e}=0.07$

$\mathrm{n}=[1.962 * 0.5 *(1-0.5) / 0.072] /[1+(1.962 * 0.5 *(1-0.5) /(0.072 * 10500))]$

$\mathrm{n}=196 / 1.0187=192.408$

$\mathrm{n} \approx 193$

The sample size (with finite population correction) is equal to 193. Simple random sampling technique was used in selecting the sample units from the population. There were 200 tea smallholders selected from Kuruwita and Pelmadulla DS divisions to satisfy the above minimum sample size requirement. The sample consists of 100 tea smallholders from each division. The contacts of the tea smallholders in each DS division were obtained from the tea smallholdings' registry of the TSHDA. In this study, primary data were collected from a cross-sectional survey of tea smallholders in Kuruwita and Pelmadulla DS in Ratnapura district. Mainly survey strategy was used for the study as it is usually associated with deductive approach and it allows collecting quantitative data within the positivistic paradigm. A pre-tested questionnaire was used as an instrument for data collection which was designed and administered under the close supervision of researchers. The main objective of this study is to estimate the technical efficiency of production by depicting the relationship between inputs and the output. Therefore, the log-linear form of the neo-classical CobbDouglas production function was used as the core theoretical framework which is explained in detail in the proceeding section.

Theoretical Framework: This study employs the stochastic production frontier approach using CobbDouglas specification to estimate the technical efficiency in tea smallholdings sector in Ratnapura district. Technical efficiency in the targeted areas of this study was estimated using 'one stage simultaneous estimation approach'. According to this approach, the parameters of the stochastic frontier and inefficiency models are estimated simultaneously, given the appropriate distributional assumptions associated with cross-sectional data of farmers in the sample (Battese \& Coelli, 1995). The noise of the estimation of stochastic frontier production function is accounted by adding a symmetric error term $U_{i}$ to the non-negative term [ (Aigner, Lovell, \& Schmidt, 1977), (Meeusen \& van Den Broeck, 1977)]. The stochastic frontier production function is depicted as follows.

$Y_{i}=f\left(X_{i} ; \beta\right)+\varepsilon_{i}$

$\varepsilon_{i}=\left(v_{i}-u_{i}\right)$

Where $Y_{i}$ denotes output of the $i^{\text {th }}$ farm, $X_{i}$ is a vector of inputs used by $i^{\text {th }}$ farm and $\beta$ is a vector of unknown parameter to be estimated and $\varepsilon_{i}$ is the composed error term. The stochastic frontier production function has two error terms. So that, $\varepsilon_{i}$ can be explained by $\varepsilon_{i}=\left(v_{i}-u_{i}\right)$. 
The term $v_{i}$ is a random variable which is assumed to be independently and identically distributed with mean zero and constant variance, $N\left(0, \sigma_{v}^{2}\right)$. It is a two sided $\left(-\infty<v_{i}<\infty\right)$ random error that represent stochastic effect outside the farmer's control (Ex: measurement errors in the output variable, weather conditions, effects of unobserved/ uncontrollable inputs on production and other statistical noise). $u_{i}$ is a one sided $\left(u_{i} \geq 0\right)$ non-negative random variable that is assumed to be independently and identically distributed with mean zero and constant variance, $N\left(0, \sigma_{u}^{2}\right)$. The term $u_{i}$ represents the technical inefficiency in production, i.e. the distribution of $u_{i}$ is half-normal. If $\left|u_{i}\right|>0$, it reflects the technical efficiency relative to the frontier. $\left|u_{i}\right|=0$ explains a farm production lies on the frontier and $\left|u_{i}\right|<0$ is a farm production lies below the frontier. According to one stage simultaneous estimation approach in which explanatory variables are incorporated in to the error component, this can be accepted (Battese \& Coelli, 1995).

According to this approach either the mean or the variance of inefficiency error component $\left(u_{i}\right)$ is considered to be a function of explanatory variables. Therefore technical inefficiency effect can be defined as follows.

$u_{i}=\delta z_{i}+w_{i}$

$i=1, \ldots, N$

Where $z$, is a vector of explanatory variables associated with the technical inefficiency effect, $\delta$ is a vector of unknown parameter to be estimated and $w$ is a set of unobservable random variables that are assumed to be identically distributed, obtained by truncation of the normal distribution with mean zero and unknown variance $\left(\sigma^{2}\right)$ such that $u_{i}$ is non-negative. The maximum likelihood method is used to estimate the parameters of both the stochastic frontier model and inefficiency effects model. The variance ratio parameter $\gamma$ which relates the variability of $u_{i}$ to total variability $\left(\sigma^{2}\right)$ can be calculated in the following manner (Battese \& Corra, 1977).

$\gamma=\sigma_{u}^{2} / \sigma^{2}$

where, $\sigma^{2}=\sigma_{u}^{2}+\sigma_{v}^{2}$

Thus, $0 \leq \gamma \leq 1$

This explains that if the value of $\gamma$ equals zero, the difference between farmer's yield and efficient yield entirely due to statistical noise.

On the other hand, a value of one would indicate that the difference attributed to the farmer is less than efficient use of technology (Coelli T., 1995). The stochastic frontier analysis is mainly directed toward the prediction of inefficiency effects (Battese \& Coelli, 1995). The most common output oriented measure of technical efficiency is introduced as a ratio of observed (actual) output $(Y)$ to the corresponding stochastic frontier output $\left(Y^{*}\right)$ which represents the maximum possible output.

$T E_{i}=\frac{Y}{Y^{*}}$

$T E_{i}=\frac{f\left(X_{i} ; \beta\right)+\exp \left(v_{i}-u_{i}\right)}{f\left(X_{i} ; \beta\right)+\exp \left(v_{i}\right)}$

Thus, the technical efficiency of production of the $i^{\text {th }}$ tea smallholder could be defined by;

$T E_{i}=\exp \left(-u_{i}\right)$

The technical efficiency index $\left(T E_{i}\right)$ equals one, if the farmer is perfectly efficient and equals zero if perfectly inefficient.

Analytical Technique: The following model specifications were used in the analysis.

Cobb-Douglas Model:

$\operatorname{Ln} Y_{i}=\beta_{0}+\beta_{1} \ln X_{1 i}+\beta_{2} \ln X_{2 i}+\beta_{3} \ln X_{3 i}+v_{i}-u_{i}$

Where, $\operatorname{Ln}$ denotes logarithms to base $e$,

$Y_{i}=$ Output (kilograms of green leaves per year)

$X_{1 i}=$ Land size (acres)

$X_{2 i}=$ labor (working hours per year)

$X_{3 i}=$ Fertilizer (kilograms per year)

$\beta_{i}=$ Unknown parameters to be estimated 
$v_{i}=$ Two-sided random error that represents factors outside the control of the farmer

$u_{i}=$ One-sided non-negative random error which represents the technical inefficiency

Inefficiency Model: The inefficiency model specified as follows (Battese \& Coelli, 1995). The model consists of farmer and farm characteristics.

$U_{i}=\delta_{0}+\delta_{1} Z_{1}+\delta_{2} Z_{2}+\delta_{3} Z_{3}+\delta_{4} Z_{4}+\delta_{5} Z_{5}+\delta_{6} Z_{6}+\delta_{7} Z_{7}+\delta_{8} Z_{8}+W_{i}$

$Z_{1}=$ Farmer's age (years)

$Z_{2}=$ Farming experience (number of tea growing years)

$Z_{3}=$ Family size (number of members in the household)

$Z_{4}=$ Level of education (number of years of schooling)

$Z_{5}=$ Age of tea plants (number of years)

$Z_{6}=$ Occupation (a dummy variable which equals one if the farmer involved in tea small cultivation only; zero otherwise)

$Z_{7}=$ Membership (a dummy variable which equals one if the farmer is a member of any farm organization, association or group; zero otherwise)

$Z_{8}=$ Access to credit (a dummy variable which equals one if the farmer has access to credit; zero otherwise)

$W_{i}=$ Unobservable random variables

$\delta_{i}=$ Inefficiency parameters to be estimated

The maximum likelihood estimates of these models and the predicted technical efficiency are obtained by using the computer software, STATA version 14.

\section{Results and Discussion}

Descriptive Statistics: The descriptive statistics for variables in stochastic frontier production function model and inefficiency model are shown in Table 1 . The results show that the total green leaves production is highly variable, ranging from 360 kilograms to 21,000 kilograms per year with a standard deviation of $3,666.02$ kilograms. The mean value of land size is 1.11 acres and it ranges with minimum and maximum values of 0.25 acres and 5 acres respectively. The average utilization of labor for the year including family and hired labor is approximately 269.64 hours with the minimum at 96 hours and the maximum at 720 hours per year. The average value of fertilizer application is recorded at approximately 573 kilograms per year which affirms that there is a larger variation in amount of fertilizer application as it ranges in between minimum value at 75 kilograms to maximum value at 1,800 kilograms per year.

Table 1: Descriptive Statistics of Stochastic Production Frontier Model

\begin{tabular}{llllll}
\hline Model & Variable & Mean & SD & Min & Max \\
\hline Production & Output (kg/yr) & 3129.96 & 3666.02 & 360 & 21000 \\
function & Land size (ac.) & 1.11 & 0.86 & 0.25 & 5 \\
& Labor (hrs/yr) & 269.64 & 138.39 & 96 & 720 \\
& Fertilizer (kg/yr) & 572.61 & 437.25 & 75 & 1800 \\
Inefficiency & Farmer's age & 52.19 & 13.08 & 29 & 80 \\
model & Farm experience & 19.58 & 9.46 & 1 & 56 \\
& Family size & 4.49 & 1.48 & 2 & 10 \\
& Education & 10.10 & 2.77 & 0 & 13 \\
& Age of tea plants & 15.35 & 7.11 & 1 & 36 \\
& Occupation & 0.73 & 0.44 & 0 & 1 \\
& Membership & 0.78 & 0.41 & 0 & 1 \\
\hline
\end{tabular}

The descriptive statistics of inefficiency model in Table 1 explain that average age of smallholders in the sample is 52 years with minimum and maximum ages of 29 years and 80 years, respectively. The average farming experience is recorded as 19 years and it ranges from 1 to 56 years. The mean value of the family size is 4 to 5 members and it ranges between minimum and maximum values of 2 and 10, respectively. The average level of education is approximately 10 years with a range of no education to 13 years and the average 
age of tea plants is 15 years ranging within 1 to 36 years. The occupation dummy variable explains 73 percent of tea smallholders are permanently engaged in tea cultivation on full-time basis and the remaining 27 percent has involved in secondary activity as well. Membership dummy variable shows 78 percent of tea smallholders is a member of any smallholders'/ farmers' union or group. The credit access is also a dummy variable and it reflects only 15 percent of smallholders in the sample have accessed credit facilities and 85 percent of smallholders have no access to credit as their unsatisfactory financial position has been an obstruction for that.

Table 2: Stochastic Frontier Estimation of Technical Efficiency Analysis

\begin{tabular}{lll}
\hline Variable & Coefficient & Standard Error \\
\hline Land size & 0.2931 & 0.06396 \\
Labor & 0.2013 & 0.07026 \\
Fertilizer & 0.8389 & 0.06323 \\
Constant & 1.8034 & 0.51367 \\
Sigma_v $\left(\sigma_{v}^{2}\right)$ & 0.4016 & 0.04218 \\
Sigma_u $\quad\left(\sigma_{u}^{2}\right)$ & 0.5218 & 0.09502 \\
Sigma ${ }^{2} \quad\left(\sigma^{2}\right)$ & 0.4336 & 0.07627 \\
Lambda & 1.2991 & 0.13026 \\
Gamma $\left(\gamma=\sigma_{u}^{2} / \sigma^{2}\right)$ & 0.6279 & \\
No. of observations & 200 & \\
Wald chi2 $(3)$ & 717.63 & \\
Prob $>$ chi2 & 0.00 & \\
Log likelihood & -185.73 & \\
Likelihood-ratio test of sigma_u & 4.51 & \\
Chibar2 $(01)$ & & \\
\hline
\end{tabular}

The above test was conducted by estimating the stochastic frontier production function and a Likelihoodratio test by assuming the null hypothesis of 'no technical inefficiency'. As indicated in Table 2, the inefficiency component of the disturbance term $(u)$ is recorded as 4.51 and it is significantly different from zero. Therefore, the null hypothesis of technical inefficiency $\left(H_{0}\right.$ : Sigma_ $\left.u=0\right)$ cannot be accepted. This implies that inefficiency is statistically significant. The lambda $(\lambda)$ value is also greater than one in all the cases. This further indicates the significance of inefficiency. The value of gamma $(\gamma)$ is 0.6279 . This implies that 62.79 percent variation in output is due to technical inefficiency. Accordingly, this confirms that technical inefficiency has a considerable impact on total green leaves production in the study area.

Estimates of Stochastic Frontier Production Function: According to the results of this model in Table 3, the p-value of land size, labor and fertilizer is recorded as 0.000 . This confirms that these three input variables are highly significant at 1 percent level of significance. Hence, land size, labor and fertilizer have given a positive and significant effect on green leaves production of the study area. The coefficients in the model explain the output elasticity of each variable of which the highest coefficient recorded is fertilizer with an output elasticity of 0.8385 . This value implies that increment of the quantity of fertilizer application by 1 percent will increase the total green leaves production by 0.84 percent. This could be explained by the observation that if the smallholders use more fertilizer kilograms per time, they can obtain larger portion of output per year. However, if tea smallholders use wrong ratios and inappropriate fertilizer variety, it might unintentionally affect their green leaves production as well.

Table 3: Maximum Likelihood (ML) Estimates for Tea Smallholdings

\begin{tabular}{lllll}
\hline Variables & Coefficient & Standard Error & $\mathbf{Z}$ & P-Value \\
\hline Land size & 0.2855 & 0.05997 & 4.76 & 0.000 \\
Labor & 0.2388 & 0.06853 & 3.49 & 0.000 \\
Fertilizer & 0.8385 & 0.05634 & 14.88 & 0.000 \\
Constant & 1.3470 & 0.47252 & 2.85 & 0.004 \\
\hline
\end{tabular}


Although the estimated ML coefficients of land size (0.2855) and labor (0.2388) explain a significant positive impact, the output elasticity of land size and labor are relatively and considerably less than that of fertilizer. The reason for the low output elasticity of land size could be the costs associated with land factor (such as land preparation cost, tea cultivation cost, etc.). These costs might have hindered the expansion of land factor which could have been highly elastic otherwise in an agricultural crop like tea. The reason for the low output elasticity of labor could be the use of unpaid family labor primarily, of which the level of productivity might be low due to informalities in application.

Determinants of Technical Efficiency: The determinants of technical efficiency were examined by using the parameter estimates of the inefficiency model. The results of the inefficiency model are depicted.

Table 4: Maximum Likelihood (ML) Estimates of Inefficiency Effects Model

\begin{tabular}{lllll}
\hline Variables & Coefficient & Standard Error & Z & P-Value \\
\hline Farmer's age & -0.0823 & 0.0460 & -1.79 & 0.074 \\
Farming experience & -0.1331 & 0.0691 & -1.93 & 0.054 \\
Family size & 0.0494 & 0.2535 & 0.19 & 0.846 \\
Education & -0.6196 & 0.2199 & -2.82 & 0.005 \\
Age of tea plants & 0.1919 & 0.0908 & 2.11 & 0.035 \\
Occupation & -2.4968 & 1.0185 & -2.45 & 0.014 \\
Membership & -6.5322 & 3.8288 & -1.71 & 0.088 \\
Credit access & -2.2343 & 1.0400 & 0.95 & 0.15 \\
Constant & 3.6297 & 3.8276 & & \\
Sigma_v & 0.4432 & & & \\
No. of observations & 200 & & & \\
Wald chi2 (3) & 757.20 & & & \\
Prob $>$ chi2 & 0.0000 & & & \\
Log likelihood & -170.74 & & & \\
\hline
\end{tabular}

In this model, a negative sign on an inefficiency parameter implies that the associated variable reduces the technical inefficiency or an increase in technical efficiency while a positive sign indicates that the associated variable increases technical inefficiency or reduce technical efficiency. The results of inefficiency model show that the level of education is highly significant at 1 percent level of significance while variables such as occupation, age of tea plant and credit access are significant at 5 percent level of significance. Although the farmer's age, farming experience and membership of a farmers' group are significant at 10 percent level of significance, family size has been insignificant in determination of technical efficiency. The results in Table 4 show that level of education is negatively correlated with technical inefficiency. It indicates that educated farmers are more efficient than less educated. The plausible reason for that is education enhances farmer's ability to make correct decisions relevant to better utilization of existing resources. In addition to that, as more educated farmers have required knowledge to access the valid and reliable information, they are capable of customizing to market changes and acquire new cultivation techniques. The coefficient of age of tea plant indicates a positive value and it implies when the tea plant is ageing, it increases the technical inefficiency (reduces technical efficiency) in tea smallholdings sector. Therefore, age of tea plant significantly influence on total green leaves production by stressing the importance of replanting to replace low productive aged tea plants. The results further reveal that famer's age and farming experience have negative and significant effects on technical inefficiency. This implies that older and well-experienced farmers are more efficient than young and less-experienced farmers. Their efficiency is due to their good managerial skills which they have possessed over time enabling them to utilize available resources in a proper manner in order to obtain a maximum output.

Further, experienced farmers have more confidence to adopt themselves to the changes in tea cultivation sector which gained over a long period of time. The coefficient of the dummy variable for occupation has negatively and significantly affected on technical inefficiency. This indicates that farmers who are only involved in tea smallholdings sector are more efficient than farmers who are involved in a secondary activity or occupation other than tea cultivation. Apparently, the reason for this disparity is that those who are involved in this sector on full-time basis are capable of giving more attention to improve their operational 
efficiency than others. Membership of a farmers' group as a dummy variable has a negative and significant effect on technical inefficiency. It implies that the smallholder who is a member of any tea smallholders' group or union is more efficient than those who are non-members. The reason is; if the farmer is a member of any smallholders' union, he/ she is exposed to new information and knowledge on problems, developments and techniques on tea cultivation activities such as plucking, fertilizing, land development, replanting and financing as well. Therefore, it will lead to increase the level of technical efficiency of tea smallholders in the study area. The dummy variable for credit access shows a negative value and having a significant effect on technical inefficiency. It means if farmers who are having better access to the credit facilities are more efficient than farmers with less access or opportunities. This implies that if farmers have more access to credit facilities, they can utilize these funds for land development and expansion, increasing fertilizer application in order to get a maximum green leaves production.

\section{Table 5: Frequency Distribution of Technical Efficiency (Cobb-Douglas Specification)}

\begin{tabular}{lll}
\hline Technical Efficiency (\%) & Number of Farmers & Percentage (\%) \\
\hline $10-20$ & 0 & 0 \\
$20-30$ & 2 & 1 \\
$30-40$ & 2 & 1 \\
$40-50$ & 5 & 2.5 \\
$50-60$ & 6 & 3 \\
$60-70$ & 12 & 6 \\
$70-80$ & 23 & 11.5 \\
$80-90$ & 81 & 40.5 \\
$90-100$ & 69 & 34.5 \\
Total & 200 & 100 \\
Mean & 0.8736 & \\
Minimum & 0.2213 & \\
Maximum & 0.9977 & \\
\hline
\end{tabular}

The frequency and percentage distribution of technical efficiency measures are summarized in Table 5. The results reveal that approximately 86 percent of tea smallholders in Ratnapura district have achieved more than 70 percent technical efficiency level and 34.5 percent of tea smallholders have achieved high level of technical efficiency ranging in between 90 percent to 100 percent. In addition to that, 6 percent tea smallholders have recorded technical efficiency level in between 60 percent to 70 percent. However, only 7.5 percent tea smallholders operate below the 60 percent level of technical efficiency. The results confirmed that the technical efficiency of study area ranges in between minimum value of 22.13 percent to maximum value of 99.77 percent. The mean technical efficiency of tea smallholdings sector in Ratnapura district is 87.36 percent. This implies that output could be further increased by 12.64 percent under the given input level and technology. Importantly, the smallholdings sector in Ratnapura district has already achieved a high level of technical efficiency compared with 63.1 percent technical efficiency of tea smallholders in mid-country region of Sri Lanka (Basnayaka \& Gunaratne, 2002). Therefore, by removing the 12.64 percent of inefficiency portion, tea smallholders in the study area can achieve maximum green leaves production using their available inputs and technology.

\section{Conclusion}

The mean technical efficiency of tea smallholdings sector in Ratnapura district was found to be 87.36 percent, implying technical efficiency of tea smallholdings sector in the study area could be further improved by 12.64 percent through better utilization of available resources with technology in existence. Although this overall efficiency level is satisfactory, 7.5 percent farmers in this area are still below the efficiency level of 60 percent. In accordance with the Cobb-Douglas stochastic frontier model, the estimated coefficients of land, labor and fertilizer positively and significantly affected the green leaves production of tea smallholdings sector in this area. This indicates that if any of these factors are further enriched, it apparently would have resulted in an increase in tea yield. Among these three input variables; fertilizer is identified as highly significant in determining the total green leaves production as it has recorded the highest positive coefficient. This requires exceptional consideration as this coefficient represents the output elasticity of the fertilizer input. The 
findings of the inefficiency model revealed that farmer's age, farming experience, level of education, occupation, age of tea plants, farming group membership and credit access have a significant effect on technical efficiency in the study area. Apparently, negative coefficients of these variables indicate that an increase of these variables will reduce the technical inefficiency. The results of the inefficiency model stressed the high significance of farmer's level of education as a farmer characteristic and age of tea plants as a farm characteristic. Further, the results highly signified the farmer's full-time involvement and credit accessibility dummies as well in minimizing the inefficiency. Therefore, it is timely important to improve the level of agriculture and farm business management related education of farmers which provides them with such knowledge on effective and efficient utilization of key inputs. Besides, this knowledge would probably provide them with skills on managing finance and labor as well. In accordance with such educational attainment, they should be given more opportunities to access the formal credit market which ultimately affect the long-term investments as the industry still has local and international growth opportunities.

\section{References}

Afriat, S. (1972). Efficiency Estimation of Production Functions. International Economic Review, 13(3), 568598.

Ahmad, M., Chaudhry, G. M. \& Iqbal, M. (2002). Wheat Productivity, Efficiency and Sustainability: A Stochastic Production Frontier Analysis. The Pakistan Development Review, 41(4), 643-663.

Aigner, D., Lovell, C. \& Schmidt, P. (1977). Formulation and Estimation of Stochastic Frontier Production Function Models. Journal of Econometrics, 6(1), 21-37.

Amos, T. T. (2007). An Analysis of Productivity and Technical Efficiency of Small Holder Cocoa Farmers in Nigeria. Journal of Social Science, 15(2), 127-133.

Basnayaka, B. M. \& Gunaratne, L. H. (2002). Estimation of Technical efficiency and It's Detrminants in the Tea Small Holding Sector in the Mid Country Wet Zone of Sri Lanka. Sri Lanka Journal of Agricultural Economics, 4, 137-150.

Battese, G. E. (1992). Frontier Production Functions and Technical Efficiency: A Survey of Empirical Applications in Agricultural Economics. Agricultural Economics, 7(3-4), 185-208.

Battese, G. E. \& Coelli, T. J. (1995). A Model for Technical Inefficiency Effects in a Stochastic Frontier Production Function for Panel Data. Empirical Economics, 20(2), 325-332.

Battese, G. \& Corra, G. (1977). Estimation of a Production Frontier Model: With Application to the Pastoral Zone of Eastern Australia. Australian Journal of Agricultural Economics, 21(3), 169-179.

Central Bank of Sri Lanka. (2013). Annual Report. Colombo: Sri Lanka.

Chirwa, E. W. (2007). Sources of Technical Efficiency among Smallholder Maize Farmers in Southern Malawi. The African Economic Research Consortium. Nairobi: AERC Research Paper 172.

Coelli, T. (1995). Recent Developments in Frontier Modeling and Efficiency Measurement. Australian Journal of Agricultural Economics, 39(3), 219-245.

Coelli, T. J., Rao, D. S. \& Battese, G. E. (1998). An Introduction to Efficiency and Productivity Analysis (1st ed.). New York: Springer.

Ellis, F. (1993). Peasant Economics: Farm Households in Agrarian Development (2nd ed.). Cambridge: Cambridge University Press.

Farrell, M. J. (1957). The Measurement of Productive Efficiency. Journal of The Royal Statistical Society. Series A (General), 120(3), 253-290.

Førsund, F., Lovell, C. \& Schmidt, P. (1980). A Survey of Frontier Production Functions and of Their Relationship to Efficiency Measurement. Journal of Econometrics, 13(1), 5-25.

Hong, N. B. \& Yabe, M. (2015). Technical Efficiency Analysis of Tea Production in the Northern Mountainous Region of Vietnam. Global Journal of Science Frontier Research, 15(1), 30-42.

Kibaara, B. W. (2005). Technical Efficiency in Kenyan's Maize Production: An Application of the Stochastic Frontier Approach. Thesis: Master of Science, Colorado State University, Colorado.

Kumbhakar, S. \& Lovell, C. (2004). Stochastic Frontier Analysis (1st ed.). Cambridge: Cambridge University Press.

Meeusen, W. \& van Den Broeck, J. (1977). Efficiency Estimation from Cobb-Douglas Production Functions with Composed Error. International Economic Review, 18(2), 435-444.

Ministry of Plantation Industries of Sri Lanka. (2013). Annual Performance Report. Colombo: Sri Lanka. 
Msuya, E. E. \& Ashimogo, G. C. (2006). An Estimation of Technical Efficiency in Tanzania Sugarcane Production: A Case study of Mtibwa Sugar Company Otugrower's Scheme. Journal of Economic Development, 1.

Nguyen-Van, P. \& To-The, N. (2016). Technical Efficiency and Agricultural Policy: Evidence from the Tea Production in Vietnam. Review of Agricultural, Food and Environmental Studies, 97(3), 173-184.

Parikh, A., Ali, F. \& Shah, M. (1995). Measurement of Economic Efficiency in Pakistani Agriculture. American Journal of Agricultural Economics, 77(3), 675-685.

Tea Small Holders' Development Authority of Sri Lanka. (2012). Annual Report. Colombo: Sri Lanka.

Wadud, M. (2003). Technical, Allocative, and Economic Efficiency of Farms in Bangladesh: A Stochastic Frontier and DEA Approach. The Journal of Developing Areas, 37(1), 109-126. 